WHY LIMEAR GIRCH AHD U $U_{5}-\mathrm{U}_{\mathrm{p}}$ EXPAHSIOAS WORK

\title{
R. GROVER
}

Physics Department, Untversity of Callfornia, Lauresce Liverwore National Laboratory. P.D. Box Bo8, Livernore, Calffornia 94550"

The equivaience of the Birch-Mursaghan equation to a 11near $U_{s}-U_{p}$ equation was 11 lustrated in the prevfous paper. Here we show in a direct manner how the virial theorem and the offect of core exclusion on vilence electron kinetic energy changes lead to the convergence of the Euterlan strain expanstion about the zero-pressure state.

\section{InTROOUCTIOH}

As in the case of the velocity expansion of shock compression data, the Eulerian finite strain expression for isotherma! pressuredensity data on solids appears to converge so well that even in the best circuostances it shows little or no evidence for quadratic strain terms.1.2 since it is both systematic and convergent, the Eulerian strain expansion seens, therefore, to represent on optinus way of characterizing the static lattice equation of state of all types of solids over extended ranges of compression. However, a general ghysical explanation of this situation has unfortunately not been reported, slthough the consistency of shock compression date with stanjard, phenomenological pseudo-potential and pair-potential models has previously been discussed, 3

Here we present a sewiquantitative explanation of the convergence of the Eulerian strain expansion from the self-consistent electron band theory of solids in the local density approxibation for exchange and correlation. This theary has provided a basis for nearly exact calculations of equation of state. properties for a great variety of sallids.
Several static lattice calculations for sibler entals have in fact been found to be wall represented by nearly linear strain expansions out to copressions of 3.2 Wit find that the virlal theores can be used with this theory to relate the bulk codulus and its higher derivatives to electron kinetic energy changes during comression. Mchahant has already Identified the latter as an important factor in changes of phise and electron bowding at high pressure. The necessary kinetic energy proparties for convergence ore then derived in a semiquantitative way from several appropriate models.

\section{VIRIAL THEOREF APPLICATIOW TO BIRCH EQUATIOH} The virtal theoren for Coulombic systans reiates the kinetic energy $t$ and potential energy $\$$ components of the internal energy $E$ to the pressure $P$

$$
\begin{aligned}
& E=t+t \\
& V P \equiv d E / d \ln p=\frac{2 t}{3}+\frac{\phi}{3}
\end{aligned}
$$

If we separate first order energy changes into scaling, $O$, and distortion, $Y$. components such as

$$
d t=d_{\sigma} t+d_{Y} t
$$

then in Hartree-Fock theory $d_{Y}=-d_{Y} t$ so that

\footnotetext{
* Work performed under the auspices of the U.S. Department of Energy by Laurence Livermore Hationa? La'Joratory under Contract $W-7$ a05-EHG-48.
} 
$d_{0} E=0$. In taking higher dertvatives of Eq. (2) to study higher compression modult the same cancellation is not completc and nore corplicated expressions result.

It is known that additlonal sind il tems nust be added to the pressure Eq. (2) in the local density approxination. A rough estinate of the correction for the Hedin-Lundquist model for exchange-correlation is $<20 \%$ of the correlation energy. Looking ahead we wlll fing that the desfred properties depend on changes in the much larger electron kinetic energles, peraitting us to drop this and other correlation corrections from further consideration.

Thus we estimate bulk roduli and their high pressure derivatives fron differentiations of (2) wth respect to density, replacing $\downarrow$ by E-t and $d E / d e n p$ by VP to get equations in tems of electron kinetic energies and $P$. For instance the bulk moduius $K$ and its first pressure derivative $X^{\prime}$. the Murnaghan paraneter. are then given at zero pressure simply by

$$
\begin{aligned}
& 3 v K_{0}=d t / d e n_{p} \equiv t^{\prime} \\
& K_{0}{ }^{\prime}-7 / 3=d \ln t^{\prime} / d e n_{p} \equiv \tau
\end{aligned}
$$

In tems of two conventent $k$ inetic energy paraweters $t$ ' and $t$.

The linear Bfrch-Murnaghan equation of state is compietely determined by these quantities. the pressure being scaied to $k_{0}$ and the coefficient of the Ifnear strain tem, $A_{1}$ by $K_{0}$ '

$$
A_{1}=3 / 2\left(K_{0}{ }^{\prime}-4\right)
$$

The convergence of the strain expansion in the rarge of presently avaflable compresston data is then adequately evaluated by looking at the next two higher strain coeffictents $A_{2}$ and $A_{3}$ which fnvolve the next two pressure derivatives of $K_{0}$. By affferentiating (2) twice more and with the use of (4) and (5) we maj write these pressura derivatives at zero pressure in dimenstonless form as

$$
K_{0} K_{0}^{\prime \prime}=-K_{0}^{\prime}+\theta\left(1-\tau / 3+d_{\tau} / d L n_{\rho}\right)
$$

$$
\begin{aligned}
& K_{0}{ }^{2} K_{0}+-2 K_{0} \cdot K_{0} K_{0} \\
& \left.\quad+\sigma[\tau-1 / 3) d \tau / d \ln \theta+d^{2} t / d(\ln \rho)^{2}\right] .
\end{aligned}
$$

Emplrically the $x_{0}$ ' is a large nusber in the range 3.5-6 for all solids of interest. The virial theorea then allows this to be dane with saller values of $T$ in the range $7-3$. according to (5), wich values we fustify in the next section in tems of the behavior of electron xinetic energy in corpression. Here we argue, miniy becauge of the large size of $K_{0}{ }^{\prime}$. that the last terus in (7) and (B) are relatfrely sall as indfeated by the nomenelature. Bropping then, wey show the sanilness of $h_{2}$ and $h_{3}$. starting from their expresstons in terms of $K_{0}$. $K_{0}{ }^{\prime}$. etc..

$$
\begin{aligned}
A_{2} & =3 / 2\left[K_{0} K_{0}{ }^{*}+K_{0}{ }^{\prime}+\left(K_{0}^{\prime}-11 / 3\right)\left(K_{0}^{\prime}-13 / 3\right)\right] \\
A_{3} & =9 / 8\left\{K_{0}^{2} K_{0}{ }^{\prime \prime}+4 K_{0} K_{0}^{\prime}\left(K_{0}^{\prime}-8 / 3\right)\right. \\
& \left.+\left(K_{0}^{\prime}-16 / 3\right)\left[\left(K_{0}-8 / 3\right)^{2}+6\right]\right\}
\end{aligned}
$$

Calculations of $A_{2}$ and $A_{3}$ in the indicated approximations (7) and (8) are show in Table 1 to demonstrate their samilness.

Table 1

$\begin{array}{llrrr}x_{0} & 3.5 & 4 & 5 & 5.5 \\ A_{2} & 0.21 & -.17 & 1.33 & 3.21 \\ A_{3} & 0.63 & 0.33 & -0.54 & 0.51\end{array}$

Together with snallness of the Eulerian strain variable $(\sim \Delta R / R)$ in the range of corpression data (<.5) the conditions ( 7 ) and ( 8 ) assure very stail non-ilinear strain contributions to the equation of state ${ }^{2}$ below compressions of 2 .

\section{MODEL CALCULATIOHS DF $\tau$}

Here we can only qualitatively describe and sumbarize our calculations of electron kinetic energy changes during compression. We use for this Durpose the cuantity t' defined by (4) which represents a characteristic amount of kinetic energy increase under infinttessimal 
anounts of compresston. According to (3) we nay dfulde this into distortional and sealing contributions,

$$
t^{\prime}=t_{T}^{\prime}+t_{0}^{\prime} \equiv \frac{d t}{d \tan s}+\frac{d t}{d \operatorname{sen} s}
$$

For example in the high density, unffom electron gas aode $t^{\prime}+t_{a^{\prime}}=2 t / 3$ and $t+2 / 3$, The logartinic derivatives of $t$ ' gtven by $x$ and its density derivatives then deteraine the convergence of the Biren-numaghan equation as Indteated in Eas. (5)-(10).

For nomal atons contributions io kinetic energy changes, t', are essentially localized to the outer, wore polartzable layers of the aton, as the higher energy valance electrons gradualiy becose excluded from a rigid ion core. Such properctes are restily seen in the electronic charge or potential oistribution given by the Thous-feral (TF) model, which model proyjdes a reslistic average nosel for equation of state. Tabie 2 presents sone direct calculations of the kinetic paraneter T. (5), wth the TF model over a wide range of tateratoatc radt ( 2 scaled).

Table 2. Kinetic energy paranezer in Thoads-fingl theory

$\begin{array}{lllllcc}Z^{T / 3_{R}} & - & 100 & 25 & 10 & 5 & 0 \\ { }^{T} T F & ?+.45 & .57 & .65 & 1.0+2 / 3\end{array}$

Thus in a Tf gas nodel of conpressfbilities ax normal densittes, ranging over $2<\tau^{1 / 3} \mathrm{R}_{0}<20$, or from aetallic $H$ to $C_{s}$. Kinetic energy changes ratse values of $K_{0}$ ' to about $2 / 3$ of nomal values accoroffig to (5) and, because of the slow variation of with density, are aiso consistent with che higher order approxitutions in Eqs. (T) a (8).

Boundary localization effects play a stronger role however in full electron-band theory caiculations of energy changes around nomal solid denstiles. Here electrons find thewselves in band states of Jefinite angular unentum (approxiateiy) which are zonfined to region outside of a fixed ion core. increosing the sensitivity of their kinetic chergy to compession of the atcaic cell. volum independent core excluslor can arise both fros the centrifugel potential in nonzero 1 states and fra orthagonalization to nuch lower states of the sale 2 in non-threshold cases. These features are indeed butit into the concept of electron pseudo-potentials and can be treated in a perturbation theory far the simpler metals. Here we try to crudely nodel kinetic energy effects in a non-Derturbatye way so as to approxinate their properties in any correct band theory calculation.

We ay first of 11 approxiente enhancement of $r$ by a staple, onz-dímenstonal gas model for radial kinetic energies in wich electrons are confined between the tifgner-Settz and inner core radif of $R$ and $R_{c}$ where

$$
R_{c}=K_{c} \mathbf{R} \text {. }
$$

In this case t refers to valence kinetic energies only and we can introduce a related quantity $\lambda$ according to

$$
\lambda=\frac{d \ln t}{d \ln \rho} \cdot \tau-\lambda+\frac{d \ln \lambda}{d \ln p} \text {. }
$$

Then simple calculations for this excluded core patential $v_{c x}$ gives the large, realistic values of $t$, when $K_{c}$ is not sall. shown in Table 3 .

\begin{tabular}{|c|c|c|c|c|}
\hline$\underline{K}$ & $1 / 3$ & $1 / 2$ & $2 / 3$ & $3 / 4$ \\
\hline$\lambda y$ & 1 & $4 / 3$ & 2 & $8 / 3$ \\
\hline TV & $7 / 6$ & $5 / 3$ & $8 / 3$ & $11 / 3$ \\
\hline dtv/denp & $1 / 4$ & 2,3 & (2) & (4) \\
\hline$d^{2}+{ }_{V} / d\left(\ln n_{p}\right)^{2}$ & $1 / 6$ & $2 / 3$ & $(2 / 8)$ & $(2 \theta / 3)$ \\
\hline
\end{tabular}

Table 2. Core size dependence of kinetic energy for $v_{c x}$ model

The large values of the higher derivatives at the largest $x_{c}$ are taken to be upper Iimits 
due to model defictenctes (see below). How this model comes to have the essential features of the kinetic energy changes is nade clear in a semiclassical treatuent of electron band states of different $L$.

The two main questions whirh are discussed here are what values of $x_{c}$ are to be used anj the adequacy of the uniform Fermingas

approximation for the electron bandstates. He use a Thonas-Femi nodel at the appropriate atonic yolune for the electrostatic part of the electron potential $v_{T F}$ in different 1 states. Thus band efgenstates are obtuined in the lowest senfelassical approximation from the radial 'phase' integral $r(c) \cdot \int_{-}^{+} k(r, c) d r$ $\equiv n_{L}$ where $\frac{k}{\sqrt{T}}-\left[c-v_{T}-(t+1 / 2)^{2} / 2 r^{2}\right]^{1 / 2}$ and the kinetic energy of a valence electron $t_{2}$ is primarily deteralned by its radial quantion number $n_{1}$ and the corresponding density of states $n_{1}=d n_{1} / d c$

$$
t_{1}=\pi n_{2} / n_{2 c}, n_{2 c}=\frac{1}{r} \int_{-}^{t} \frac{d r}{k_{2}}
$$

It is well know that valence electron states are largely excluded from core states because of overlap with lower energy bound states of the same or because of the centrifugal petential for 'threshold' cases where no bound state exist. If we represent this by an enpty-core electron pseudopotential we thoy obtain a realistic estinate of $R_{c}$ (and $K_{c}$ ) by requiring $n_{\ell}=1 / 2$ for electrons at the Fermi energy. Such estinates agree closely with electron potentials in atals calculated by electron band theory nethods. 7 Representative examples are given in Table (4) calculated with Thomas Fermi potentials. Carbon is an example of a threshold s-state (1.e., a pstate) with a typical small sore. but in most cases salids with p-state bonding experíence large phase transitions on compression and are not of interest here. Rb has a larger 45 orthogonalization core and in ag the 45 core $K_{C}$ is especially large because of tts high density due to strong resonance bonding of the 4d electrons. Experinental values of $K_{0}$ ' also increase dramatically fron C to Ag consistant with the increase in their $K_{c}$ 's.

Table 4. Seatclassical calculations of in Thoms-Fermil potential

\begin{tabular}{|c|c|c|c|c|c|}
\hline Element & $2^{1 / 3} R_{0}$ & $\pi F$ & $k_{c}$ & $\tau_{0}$ & $n$ \\
\hline$c$ & 3.62 & $>1$ & -.2 & - & -1.0 \\
\hline $\mathbf{R b}$ & 19.0 & -.6 & -.35 & -1.7 & - \\
\hline Ag & 11.0 & -.65 & -.65 & $-\infty$ & - \\
\hline
\end{tabular}

Sentclassical values of $\lambda_{2}$ from Eq. (14) for particular band states in a fixed vif are also show in Tabie 4 and they inply a tequai to or greater than values in Table 3 at the corresponding $K_{f}$. Additional calculations including the effect of self-consistency as well as band averaging will be presented in a later. wore conplete puolteation.

\section{REFEREHCES}

1. R. Jeanloz and R. Grover (previous article this volune).

2. R. Grover, Btrch Expansions Beyond 2-Fold Conpression, Lawrence Livertwore Nat. Lab. UCRL-95388 \{1986\}.

3. A.L. Ruoff, J. Applied Phys. 38 (7967) 4976 S.P. Singh, Phys. Rev. B, 9 (1973) 3313 K-J. Dunn, Phys. Rev. B, 12 (1975) 3497.

4. A.K. Mchahan, Physica 139 \& 140 B (1986) 31.

5. 0.J. Steinberg. J. Phys. Chem. Solids 43 (1982) 1173 .

6. Note the sritiness of $A_{2}$ and $A_{3}$ in table 1 arise from Eq. (7), requiring that roots of $A_{2}$ be $11 / 3$ and $13 / 3$ and $E q$. (8), that $A_{3}$ 's roots are $(11 \pm \sqrt{ }) / 3$ and $76 / 3$ !

7. Y.L. Horuzz1, J.F. Janak, A.R. Williams, Calculated Electronic Properties of Heta1s, (Pergamon Press Inc.. Hew York, 1978). 


\section{DISCLAIMER}

This report was prepared as an eccount of work sponsored by an agency of the United States Goverament. Neither the United States Government nor any agency thereof, nor any of their erzfloyees, makes any warranty, express or implied, or assumes any legal liability of r=sponsibility for the accuracy, completeness, or usefulness of any information, apparatus, product, or process disclosed, or represents that its use would not infringe ptivately owned rights. Reference hertin to any specific commercial product, process, or service by trade name, trademark, manufacturer, or otberwise does not necessarily constitute or inply its endorsement, recommendation, or favoring by the United States Governmeat of any agency tbereof. The views and opinions of authors expressed berein do not necessnrily state or reflect those of the United States Govertment or any agency thereof. 